\title{
The bowel habit of young children
}

\author{
L T WEAVER AND H STEINER
}

University Department of Child Health, Royal Victoria Infirmary, Newcastle upon Tyne

SUMmaRY The bowel habit of 350 preschool children from a single general practice was studied. Eighty five per cent of 1 to 4 year olds eating a predominantly low fibre diet opened their bowels once or twice a day and $96 \%$ of the children fell within the range of three times a day to every other day. At all ages most children produced soft stools of about $25 \mathrm{ml}$ volume. Mean intestinal transit time of $35(10 \%)$ randomly selected children was 33 hours. There is a significant correlation between infrequency of bowel action, longer transit time, hard stools, and the passage of blood.

There are no systematic studies of the normal bowel habit of preschool children. By this term we mean the frequency with which children open their bowels, the size and consistency of the stools, and the time that food takes to pass through the gut. We report the results of a study of the bowel habit of a population of English preschool children.

\section{Methods}

All preschool children aged between 1 and 4 years, from a single general practice in Cramlington New Town, Northumberland were studied. Three health visitors used a questionnaire to record what mothers regarded from observation to be their children's normal bowel habit and a dietary history.

A set of plasticine stools of different volumes (stercometer) was used to help mothers judge the size of their children's stools. These were the size of a grape $(5 \mathrm{ml})$, a small sausage $(25 \mathrm{ml})$, and a large sausage $(40 \mathrm{ml})$.

Mouth to anus transit times of $35(10 \%)$ randomly selected children from the study population were measured using carmine marker. Carmine $(200 \mathrm{mg})$ added to $7.5 \mathrm{ml}$ concentrated black currant juice diluted to $50 \mathrm{ml}$ with water makes a palatable solution well tolerated by children. This was taken on rising in the morning and the time when the stool was first noted to be red was recorded by mothers. Transit times were expressed in two ways:

(1) The time (in hours) between the ingestion of carmine (input time) and the first red stool (output time).

(2) The number of bowel actions between carmine input and output times.

The study was performed in 1981 with the approval of the local ethical committee and the informed consent of parents. The Mann-Whitney $U$ test was used to test the significance of the transit studies and the $\chi^{2}$ test for the rest of the data.

\section{Results}

All 350 children from the practice between the ages of 1 and 4 years were studied; 95 were aged 1, 102 aged 2, 95 aged 3, and 58 aged 4 years. There were 179 boys and 171 girls and $68 \%$ belonged to social classes III or IV. Dietary history showed that all children ate a predominantly low fibre, mixed diet consisting typically of cereal or porridge, toast or bread, and milk, juice, or tea for breakfast; biscuits, crisps, or juice mid-morning; sausages, tinned spaghetti, fish fingers, beans, and chips for lunch; biscuits, crisps, sweets, and juice at tea time; and an evening meal of much the same composition as lunch. No significant differences between boys and girls were observed for any of the findings described below.

Frequency of bowel action. Eight five per cent of the children opened their bowels once or twice a day and the percentage opening their bowels once daily increased year by year $(r=0.9)$ with a corresponding decline in the percentage opening their bowels more frequently. Ninety six per cent fell within the range of three times a day to every other day. Only 20 children $(6 \%)$ opened their bowels less than once a day-7 of these children had had treatment for constipation in the past, 6 had passed blood in the stool at some time, two had recognised developmental delay, and one had had a small intestinal resection as a neonate. Sixty five per cent of the 649 
children opened their bowels after meals; $31 \%$ in the morning, $16 \%$ after noon, $23 \%$ at both times, and $30 \%$ anytime. The frequency of bowel actions is shown in Figs. 1 (a) and 2.

Size of stools. At all ages most children produced small sausage sized stools $(25 \mathrm{ml})$ and less than $10 \%$ produced grape sized stools $(5 \mathrm{ml})$ (Fig. 1 (b)).

Consistency of stools. At all ages most children produced soft stools, though there was a year by year decline in the percentage doing so and a corresponding rise in those producing hard stools $(r=0.9)$. Those children who opened their bowels less than once a day produced significantly harder stools $(P<0 \cdot 002)$ but there were no other significant correlations between frequency, size, and consistency of stools (Fig. 1 (c)).

Transit studies. Mean mouth to anus transit time in the 35 children in which this was studied was 33 hours. The transit time in the 18 children who were aged less than 3 years was mean (SD), 30 (18) hours and was $36(13)$ hours in the 17 children aged more than 3 years $(\mathrm{P}<0.05)$. There was, however, no significant difference between the two groups when transit times were expressed as mean number of bowel actions per transit time $(\mathrm{P}=0 \cdot 15)$.

Blood in the stools. Nine per cent (32) of the children had passed blood in their stools at some time; $19 \%$ (6) of these opened their bowels less than once a day compared with only $4 \%$ (14) of those children who had never passed blood $(\mathrm{P}<0 \cdot 03)$. There was no

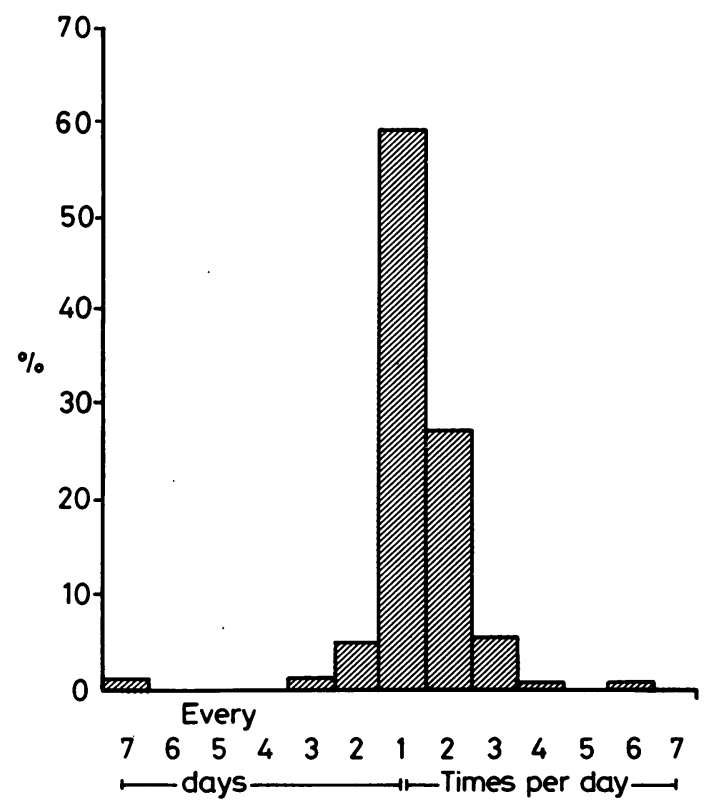

Fig. 2 Frequency of bowel actions in a cohort of 350 children aged between 1 and 4 years.

significant relation between the passage of blood and the size or consistency of stools.

'Bits of food' in stools. Mothers observed 'bits of food' in the stools of $73 \%$ of 1 year olds, $52 \%$ of 2 year olds, $27 \%$ of 3 year olds, and $17 \%$ of 4 year olds $(r=0 \cdot 9)$. (a) Stool frequency

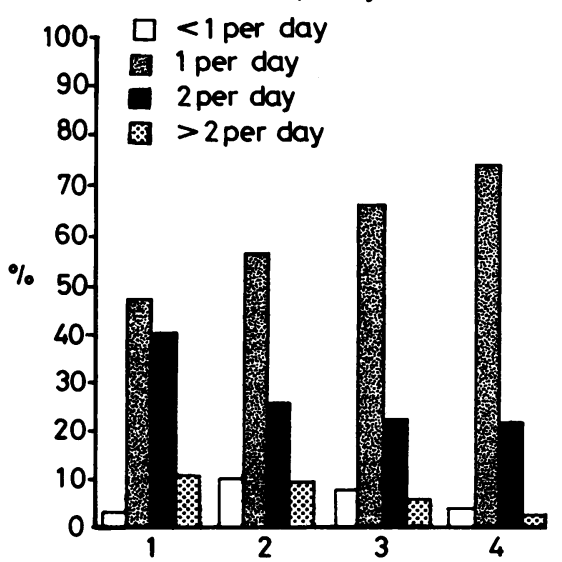

(b) Stool size

$25 \mathrm{ml}$ (small sausage)

国 $40 \mathrm{ml}$ (large sausage)

口 $5 \mathrm{ml}$ (grape)

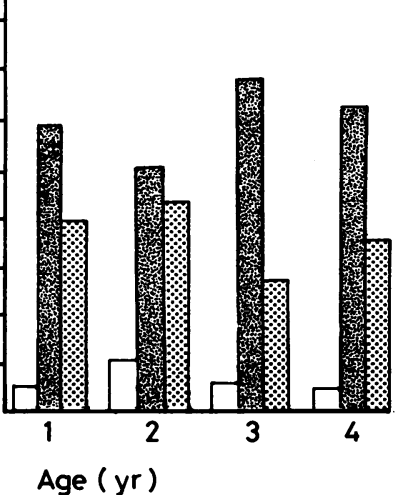

(c) Stool consistency.
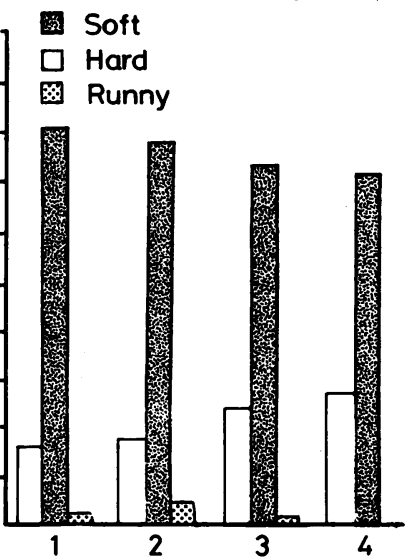

Fig. 1 Stool frequency, size, and consistency in a cohort of 350 children aged between 1 and 4 years. 


\section{Discussion}

The typical preschool child eating a low fibre diet opens his bowels once daily (after breakfast), produces a soft stool of about $25 \mathrm{ml}$, and has a whole gut transit time of 33 hours. Although these findings may not seem unexpected; an informal local survey of 33 paediatricians and others involved in the care of children showed that $62 \%$ thought that the typical 1 year old child opened his bowels more frequently than once a day, and many regarded the normal range to extend from five times a day to three times a week. As we have shown, the normal range is very much narrower-only $4 \%$ of children opening their bowels more frequently than three times a day or less than every other day (Fig. 2).

A daily bowel action is the norm for adults too. A survey of 1455 adults found that five to 7 bowel actions a week was typical and that $99 \%$ fell within the limits of three daily to three per week. ${ }^{1}$ Only $6 \%$ of 1115 postal workers ${ }^{2}$ and less than $9 \%$ of 440 nurses $^{3}$ had less than one bowel action per day. Twenty long stay geriatric patients had a mean number of bowel actions a day of $0.7 .^{4}$

Putting our data in chronological context (Fig. 3), our finding of a yearly decline in mean frequency of bowel actions between 1 and 4 years of age follows the steady monthly decline described by Wolman who studied 1000 babies aged 12 to 24 months. ${ }^{5}$ Lemoh and Brooke in a study of 55 infants ${ }^{6}$ showed a decline in frequency from four bowel actions a day during the first week of life to 1.7 during the second year and Nyhan, who studied 800 newborn babies, identified a peak frequency of 4.4 at 5 days of life. ${ }^{7}$

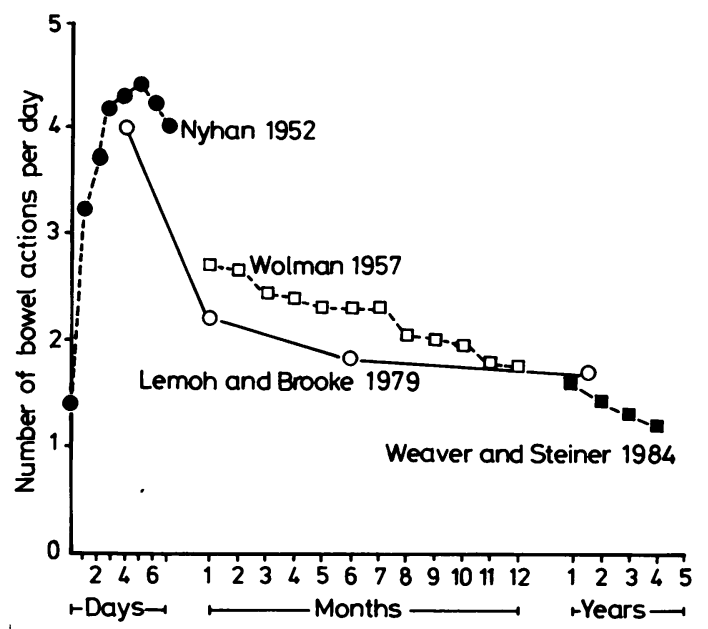

Fig. 3 Mean frequency of bowel actions from birth to age 5 years.
The main decline occurs during the neonatal period but there may be a later one around the onset of solid feeding, as suggested by the drop in stool frequency from 2.3 per day at 7 months to 1.7 at 1 year.

The decline in frequency of bowel actions with age correlates with increasing whole gut transit times. Lesné et al, using carmine marker, showed a rise in transit time from a mean of 8.5 hours in infants aged 1 to 3 months to 10 hours in infants aged 1 to 2 years. ${ }^{8}$ Triboulet found a mean transit time of 16 hours in a group of infants of 4 to 24 months. ${ }^{9}$ Dimson, comparing the transit times of a group of constipated children with normal children of 3 to 13 years, found a mean transit time of 26 hours in the latter group ${ }^{10}$ and Burkitt, studying English boarding school pupils, found a mean transit time of 57 hours. " English adults have been found to have mean transit times ranging from 30 hours to 48 hours ${ }^{11}$ and geriatric patients in hospital of one to two weeks. ${ }^{4}$

The relation between whole gut transit time and the frequency of bowel actions is not emphasised in all studies. If a marker is taken at the time of a bowel action, transit time cannot be shorter than the interval between two bowel actions: the more infrequently the bowels open the longer the transit time. Our data suggest that whole gut transit time and frequency of bowel action are closely related. Burkitt has described an inverse relation between stool weight and transit time-those groups eating a diet rich in fibre producing large stools more often than those eating one of low residue who pass small stools infrequently. ${ }^{11}$ The infants we studied all ate a predominantly low fibre diet. We did not perform transit studies on those children who opened their bowels less than once daily but Dimson has shown a significant correlation between infrequency of bowel action and prolonged transit time in constipated children. ${ }^{10}$ Our data also show a positive correlation between infrequency of bowel action and the passage of blood and hardness of the stool.

To study the relation between the frequency of bowel actions, the size and consistency of the stool, and transit time more closely we suggest that a study similar to ours be performed in a population of preschool children eating a high fibre diet.

Burkitt, referring to the contrasting pattern of gastrointestinal diseases in Africa and Europe, complained how can we begin to advise British parents advantageously to alter the stool charactersitics of their children until we know what they now are? ... Only one of the many paediatricians who have undertaken to obtain this information has managed to accomplish what is apparently an almost insuperable paediatric problem-to weigh a stool'. ${ }^{12}$ 


\section{Weaver and Steiner}

We hope that using our stercometer to estimate stool size, our data go some way to answering his appeal.

We thank Miss E Jackson, Mrs A Fawcett, and Mrs A Logan, health visitors, who collected most of the data; Drs A Dove and $C$ Ward in whose practice the study was performed; and the parents of the children described.

\section{References}

1 Hinton JM, Lennard-Jones JE. Constipation: definition and classification. Postgrad Med J 1968;44:720-3.

2 Parks JW. MD Thesis. Bowel habits: an investigation based on the examination of 1115 male adults. Cambridge: Cambridge University, 1943.

${ }^{3}$ Hardy TL. Order and disorder in the large intestine. Lancet 1945;i:519-24.

4 Brocklchurst JC, Khan MY. A study of faecal statis in old age and the use of Dorbanex in its prevention. Gerontologia Clinica 1969:11:293-300.
5 Wolman IJ. Laboratory applications in clinical pediatrics. New York: McGraw Hill, 1957:696-7.

${ }^{6}$ Lemoh JN, Brooke OG. Frequency and weight of normal stools in infancy. Arch Dis Child 1979;54:719-20.

${ }^{7}$ Nyhan WL. Stool frequency of normal infants in the first week of life. Pediatrics 1952:10:414-25.

${ }^{*}$ Lesné E, Binet L. Paulin A. La traversee digestive chez le nourrisson variations biologiques et pathologiques. Archives de Medicine des Enfants 1920:23:449-56.

${ }^{9}$ Triboulet H. Duréc de la traversee chez l'enfant malade. Epreuve du carmin. Bulletins de la Societe de Pediatrie de Paris 1909;11:512-29.

10 Dimson SB. Carmine as an index of transit time in children with simple constipation. Arch Dis Child 1970;45:232-5.

" Burkitt DP, Walker ARP, Painter NS. Effect of dietary fibre on stools and transit-times, and its role in the causation of disease, Lancet 1972;ii:1408-11.

12 Burkitt DP. Stool weights in Western children. Lancet 1976;ii:633.

Correspondence to Dr L T Weaver, Department of Child Health, Royal Victoria Infirmary, Newcastle upon Tyne NE1 4LP.

Received 21 March 1984 